
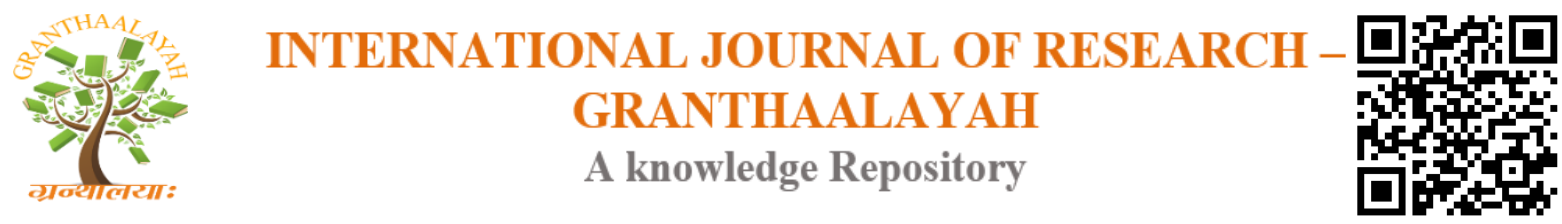

Social

\title{
EDUCATION FOR PEACE AND THE ETHICAL DIMENSION IN PROFESSIONAL TRAINING PROCESSES
}

\author{
Dr. Gabriel Mendoza $M^{* 1}$ \\ ${ }^{1}$ Ph.D., University of Sonora, México
}

\begin{abstract}
The present text deals with aspects concerning the integration of concepts conferred to the instruction of the ethical dimension, in processes of formation of the common axis in professionalization and university incursion, as a strategy promoted in education for peace. Based on transdisciplinary approaches, which allow addressing said emblem from an integral perspective. Allowing itself, to explore the different perceptions emanated from those who are in the process of formation, from methodological premises of an exploratory descriptive nature, taking as an initial axis the semi-structured interview with 5 groups of students of a public university, out of a total of 25, assigned to different areas of knowledge, whose common feature is the course of materials and content in the ethics instruction within the professional practice and its participation in the rubric of education for peace. In this way, general perceptions are generated, which allow us to investigate possible conceptions that are currently found in the group undergoing formation. Delimited in this way, broad strategic possibilities for the formation of instructional content aimed at adequate comprehensive understanding, constituted in current processes of education for peace.
\end{abstract}

Keywords: Education for Peace; Ethics; Professional Training; Transdiscipline.

Cite This Article: Dr. Gabriel Mendoza M. (2019). "EDUCATION FOR PEACE AND THE ETHICAL DIMENSION IN PROFESSIONAL TRAINING PROCESSES." International Journal of Research - Granthaalayah, 7(4), 37-45.

\section{Introduction}

One of the main premises in the professional training programs is to generate professionals with a comprehensive approach, committed to their contribution to the development of the contexts of which they are a part, and from which an appropriate contribution would be expected, capable of promote improvements in more than the areas of reality itself. In such a way, that the strategy of training in topics oriented to topics such as education for peace, are instrumented from multiple strategies or cross-cutting contents that allow a greater understanding and assimilation, before the possibility of integrating the knowledge reviewed in each of the disciplinary areas of university education, in this case the ethical dimension, as an integral proposal. 
In this sense, it refers to the different stages or blocks that make up the current training proposal in the instruction of ethics formation, within the university space, as well as part of the sequences or contents proposed in the instructive exercise, as a promoter of schemes attached to the processes of education for peace.

The general objective of this inquiry is to promote the appropriate context in which to reflect on the universal issues concerning the ethical aspect in professional preparation, as well as an integral citizen, committed to his social contribution, and aware of their global interrelation, oriented to the application of knowledge emanating from the profession, with a human vision.

Positions that authors such as Camps, (1998) ${ }^{1}$, already referred to, regarding the importance of the instruction and review of academic topics within the professionalization processes, with attention capacity towards the broadest opportunities of solvency or resolution of real challenges, in the different current contexts; as well as suggest viable improvement proposals. In such a way that the knowledge acquired in the programmed areas of professionalization, had a real agreement with the environment and its own development, in this sense the integration of the ethical emblem and its scope in the education for peace scheme.

Hence the schematization of the various blocks suggested as sequential axes, in which it is possible to enter didactically, with each of the proposed sections, which are understood at first, with the theme related to culture and values, from where the reflection of the different expressions emanating from the multiple contextual contexts that provide the cultural expression is urged.

Emphasizing the corresponding context, where the individual is a part, and from where it is possible to interpret their surrounding reality. The norms and values, from which it was formed during its first years of life and development. Likewise, the allusion concerning the manifestation of different understandings and cultural developments, exercised in other latitudes, from where the optics and conceptions of life become, starting from a scheme different from those that in a conventional way, it has integrated as part of a socio-cultural context defined, but not superior. In this sense, the opportunity to explore dissimilar configurations, in turn, promote tolerance and respect for different modes of existence, which allow expanding the areas of understanding.

In a second block, the identification of the differences between ethics, morals and values corresponding to the impact on the development of moral autonomies is promoted, from the presentation of dilemmas that urge awareness of responsibilities, from the use of the liberties, individual and social, in topics such as: justice, loyalty, compassion, truth, individual, community, and each of the multiple implications that the participative act, consciously or not, is linked to, from the everyday scenario. Likewise, the socio-historical review exercise, in which the conceptions of what has been made manifest and the ways in which the various changes of a social nature have led to adjustments according to the situational schemes. As well as, the emblems that have been consolidated and permeated in each of the stages of human, formal social development.

Stances that authors such as Markova et al. $(2017)^{2}$, already referred in the sense of making synergies in a very specific way between the vocational training structures and the real promotion of coherent positions before the different items of the immediate context in which access to the 
attention capacity is achieved; but also to start, from a promoter base itself, the different current values of a socio contextual nature, which would allow relevant developments.

In this sense, the sequencing of a third segment, contained in the precept of social values, as a set of values, from which it is necessary to promote towards the construction of a community in which the possible recognition and right of manifestation is spilled, as well as the responsibility for the acts emanating for each of its members. As participatory entities and with creation of social significance. Approaching like this, conceptions such as: the interpersonal relationships, the scopes, characteristics and foundations that promote the healthy interrelation from the recognition of the existences and multiple integrations. The sensitization of the humanistic sense in the social act, promoted from the principles of tolerance, respect and solidarity, configured from the care and procuración of healthy surroundings, propitious for the general development of its members.

Proposals in themselves, referred to the consolidation of programs with the impetus of an integral formation that allows in a truthful way, to consolidate current orientation platforms and with flexibility of constant reconfigurations, that focus in a specific way on the changing evolutionary cycles, Segreda, et al. $(2014)^{3}$.

Hence the expression oriented to a fourth segment, in which the ethical dimension of professional development is raised, within the assessment of professional activity as part of a personal and social development with the ability to apply the principles that underpin ethics as an essential axis in the proper exercise of the discipline as a profession constituted from a position of service towards the environment and the global context, in an integral manner, with capacity for reflection and constant improvement.

Being these, part of these schemes of incursion, poured into the block of topics to review during the development of the scheme as such; also noting the proposed teaching strategies to be considered, in which they are exposed from a transdisciplinary participatory methodology, in which it is possible to sequence a breakdown with a capacity for gradual understanding, in which, in addition to the revision of the proposed concepts, achieve the appropriation and formal understanding of the different terms, their appropriate applicability and integration in the different conditions of the global context, as well as the achievement of a consensual criterion, where the professional characterization itself, allows to approach conceptions of the own situational dynamics, where it is allowed to integrate the same daily life. With premises constructed from reflective approaches, with management capacity and feasible execution, in as much as the precisions of the same professions.

Alluding to this form, the experiences derived from research processes such as the present proposal refers to, in which it is possible to inquire about the opinions and reflections made by groups that are precisely within vocational training schemes, and who, in turn, they focus on socio-contextual spaces with specific requirements, in terms of their adequate participation before and during the integration segments. 


\section{Materials and Methods}

This research was conducted within a university context of professional training of a public university, and specifically, the university of sonora, with students, who are comprised in five divisions of the Institution.

Delimiting, to five of each of them, and adding a total of 25, of the different academic disciplines, but that have as criterion of fundamental inclusion, the course of ethics and professional training, within their different curricula and of all of them who had already accredited more than half of their credits or training courses.

Signaling the research schemes within the exploratory descriptive parameters, which in turn allowed to concatenate their assessments resulting from the in-depth interview of each of the groups in an individualized manner; in such a way, that it was possible to clarify, the notions assumed with respect to the subject of ethical training, as well as its contribution in crucial topics such as education for peace, as part of the integral formation in each one of its disciplines. Where would be supported appreciations such as Marradi, et al. $(2010)^{4}$, who refers to the importance of interrelating the opinions expressed by the participants themselves, with the slogan of verifying the significance in research processes.

Within the interview, and emphatic foray into the qualitative approach, positions such as that of Ruiz, (2012) $)^{5}$, who argues, that is from this exercise in which they achieve closer comprehensions, in terms of the conscious emission of those who are formally assigned to processes and development of training, and who in turn are participants in exploration processes. According to the number of participants indicated, the distribution and general characteristics are presented in the following table, as well as the disciplinary division, which corresponds to the exact sciences, humanities and arts, social sciences, biological and health sciences, as well as the economic administrative, within which each of them would be found. (see table 1).

Table 1: Key features of participants.

\begin{tabular}{|c|c|c|c|}
\hline \# of informant & Gender & Age & Academic Division \\
\hline 1 & Man & 23 & exact Sciences \\
\hline 2 & Woman & 22 & social Sciences \\
\hline 3 & Woman & 23 & exact Sciences \\
\hline 4 & Man & 23 & humanities and arts \\
\hline 5 & Woman & 23 & exact Sciences \\
\hline 6 & Man & 22 & humanities and arts \\
\hline 7 & Man & 22 & social Sciences \\
\hline 8 & Man & 23 & economic administrative \\
\hline 9 & Woman & 23 & biological and health \\
\hline 10 & Man & 24 & biological and health \\
\hline 11 & Man & 23 & economic administrative \\
\hline 12 & Man & 24 & exact Sciences \\
\hline 13 & Man & 23 & economic administrative \\
\hline 14 & Woman & 24 & social Sciences \\
\hline 15 & Man & 23 & biological and health \\
\hline
\end{tabular}




\begin{tabular}{|c|c|c|c|}
\hline 16 & Man & 23 & economic administrative \\
\hline 17 & Woman & 23 & exact Sciences \\
\hline 18 & Man & 22 & humanities and arts \\
\hline 19 & Man & 23 & biological and health \\
\hline 20 & Woman & 24 & economic administrative \\
\hline 21 & Man & 23 & social Sciences \\
\hline 22 & Woman & 23 & biological and health \\
\hline 23 & Woman & 24 & social Sciences \\
\hline 24 & Woman & 24 & humanities and arts \\
\hline 25 & Man & 23 & humanities and arts \\
\hline
\end{tabular}

Source: self-made.

As part of the research instruments, the interview was used, which was constituted in ten questions addressed to a general exploration, referring to the perception with which the notions that participants have regarding the contents of assimilation ethics in their professional training, as well as the aspect of education for peace as a strategy of general integration during their formative stage. Delimiting these issues to three general items, contained in the general perception exposed to the ethical incursion, its interrelation with the specific theme of education for peace, and the degree of integration assumed as a position of disciplinary integration of joint participation.

From the data obtained, the information was analyzed based on the saturation technique, through the Atlas.ti software, from which, through its functions, an exploration of findings is allowed to concatenate the reflections emitted during the exercise exploratory and its integration to the main conceptions issued by the attached participants, based on their answers, and suggested comments.

\section{Results and Discussions}

\section{The Ethical Foray}

Within the answers given by those who made up the different groups of exploration were different reflections that allude to a global understanding concerning the ethical precept as a fundamental part in professional training, and in its conscious assimilation of the scope that for professional practice this confers, not only from a personal perspective, but also collectively, and with a universal incentive. In this sense, part of the arguments referred to focus on positions that the participants mention, such as:

"The ethics issue, if not included in the different university education programs, would be incomplete for true participation".

Informant 2

"Only by fully understanding what ethics provides is when you can assimilate commitment as a professional future”. Informant 6

"Since the review of ethical content as such, the concern to investigate a little more has been present in each of the subsequent subjects".

Informant 10 
"The implication that the ethical concept itself confers, is related in a broader way, with the interactions of the context".

"In a way, these backgrounds would always accompany the development of the professions in all their spheres".

Informant 21

Referring in this way key assimilations, such as those of Navarro et al. (2018) ${ }^{6}$, who alluded to the fact that during the processes of professional training, one of the elements of vital consideration would be the structure of formal responsibility, which is assumed, not only from the professions that integrate more directly to the social construction, but it would also encompass, to a certain extent, their participation would be perceived in a more indirect way, but with equal integration rates.

Defining in this way approaches, which allow to integrate in turn, the topics that in a certain way are established as baseline elements in the construction and development of the multiple current contexts, and that from formative precepts, are ordered in a subsequent way, in as much to the dissemination and strategic implementation of items concerning an integrative education, and in this sense that of an education for peace, from a transversal perspective, with capacity for interrelation and comprehensive training.

\section{Interrelation in Education for Peace}

Within this premise, the reflections derived from the exploratory process, promotes a constant assimilation, both of the component topics of the training field, as well as of the own position of disposition and common commitment in the specific development of emblems that provide a formal conceptualization that they are sustained, not only in the requirements of essential consideration in the segments of social progression, but they are present in the different sketches or general progress plans, of those who make up the multiple social scenarios in the current level.

"I believe that the specific theme of peace and all its significance, is involved in individual and collective formation, in each and every one of the stages of existence".

Informant 4

"The issue of peace, I am interested, if considered, that is part of an adequate coexistence in all its areas, of which I am also a part".

Informant 12

"I have reflected on this concept, even before thinking about pursuing a university education, I consider it an essential part of coexistence”.

Informant 15

"Perhaps, we should not wait for adverse situations to appear, to include these contents in the academic preparation of the different professions".

Informant 19 
"In addition to being present in any of the training spaces, education for peace as such, should be considered, not only in the strata of professional nature, but from the very beginnings and academic degrees".

Informant 24

Positions that are integrated, not only from the consideration, scope or degrees of importance that the rubric provides, but also; integratively, it is shown with characteristics of great significance in each and every one of those who make up the different participatory groups. In this sense the offered arguments permeate with appreciations that authors like Lotz (2014) ${ }^{7}$, already mentioned, with respect to the different statutes and comprehensive precepts that obey each one of the confluent individuals in the same shared space, from which an imperative signification arises, in as much to the collaborative co-responsibility that it provides, to be conscious and oriented towards the achievements with capacity of direct and indirect repercussion with admissible incitements to a suggested expansion and punctual development of all the areas of the socio contextual context.

That is, from the point where there is a successful conjunction, both objectives, and premises to follow, and whose bases warn from emblems of consideration and related achievements, both the proper contextual development, as well as environmental partner, of those who make up this entity. It would be precisely, from said actors, from where a constant and firm sequencing and consequent responsibility would be promoted that allows said precisions, Porter $(2006)^{8}$.

\section{The Integral and Transdisciplinary Participation}

A way to understand the scope that the own disciplinary interaction allows from its own integrative position, is presented from the multiple experiences that these dynamics have been patented during the different stages of global common development. Perspectives, which have allowed us to see, not only the consequent answers, towards the most diverse challenges of multiple propositions; It has been precisely from where, in a relevant way, the premises developed and implemented towards the multifactorial resolution, it has been possible to appreciate the real achievement and timely permission, from inter and transdisciplinary participation Lanz, (2010) ${ }^{9}$. In this sense, to achieve a gradual understanding towards this perspective, will be able to infer, towards the multiple possibilities, besides the routes to follow; in person, but also sequentially. Emiting this way, to the different conceptualizations, that urge to a real impression that is possessed and from where it is possible to verify premises like the present investigation.

"Learning even one or several fragments of other disciplines, allows you to expand your spectrum and comprehension capacity”.

Informant 1

"One of the achievements that I consider with greater significance, is the gradual integration of contents, which although they originate in other areas of knowledge, they are allowed to interact". Informant 8

"I would understand the transdiscipline, as the ability to participate from multiple areas of knowledge, for purposes of a common way and shared benefits".

Informant 13 
"The integration or participation with other areas of universal education has been getting closer and closer to the different vocational training programs".

"I have had experiences with great pleasure, based on coincidences with other groups of academic formation, and the results considered can be quite proactive".

Informant 18

From this point of view, the immersion of the different fields of knowledge, which, although originally, focused exclusively on solving and attending to specific feats in their different areas of activity. Their own achievements and advances, allowed to envision, the wide possibilities of achievement that would be poured from the simple permission to venture beyond the exclusive spectrums of conceptual definition attached to each of the disciplines conforming universal knowledge Morett, (2010) ${ }^{10}$. Thus, the initially multidisciplinary, interdisciplinary, and later transdisciplinary format generates precisely the sequential support, which not only provides the subsequent attention responses, but also redefines and dimensions the very notions of a crucial incursion.

In this way, innovative conceptions, with the capacity to reconfigure, and the implementation of multiple strategies and prowess, until then absent from the contextual framework, with the capacity to act, before the new scenarios, both current and prospective, Haavelslrud $(2015)^{11}$.

Hence the importance of considering the reflections that have emerged from the different fields or divisions of knowledge, which in this study are shown from groups in formation, from where one can contemplate, the degrees of comprehension, that before the topic of ethics, it is contained; as well as that of its subsequent integration of premises formed in the field of education for peace, as an emblem of insertion based on its consideration and position of interrelation in the different training processes.

\section{Conclusions and Recommendations}

From the elements shown, reference is made to the general description of each of the sections corresponding to the program of professional ethics; in which, in a proactive way, the integration of reflections that would allow a greater understanding of the proposed content, in which the updating of the different items is promoted, to the current, multidiverse and changing contexts, in which pertinent a constant functional appreciation, as well as the one of the professional incursion, that suggests the own disciplinary specification. From where, in addition, it is considered prudent to update itself, of who served as instructor, in the incursion of the discipline as such.

From where it is shown, in a proactive manner, that it is precisely those who make up the structure of a formative nature or who serve as the instructor base; from where, an adequate and precise assimilation was constituted, with real commitment of the scopes and formal criteria, towards joint action and participation. Orientated in itself, to the different training processes, but that from these principles, co-responsibility, is achieved, as a position of professional nature and socio-contextual awareness. 
Also suggesting the reflexive incitement, towards the correct applicability exerted in other contexts, with assimilation schemes, perhaps different to the contextually recognizable ones and of eventual presence, or rather than from the experience raised in other regions of the global scope, and whose strategies of incursion, foundation and achievement, have been successfully developed, in an appropriate way in their socio-contextual environment. These premises could be studied and implemented for such purpose, in the current surrounding scenario.

Also, the facilitation and integration of contemporary materials that promote a constant inquiry, reflection and awareness of topics related to this segment of comprehensive training. In addition to the exercise of experiential character dynamics that allows to explore conceptions that hover to a situational precept, and of personality from which, it is possible to be dimensioned towards an understanding of greater scope. From where also, it is noticed, the premise of contribution to the conformation of an integral professionalization reflective and with plural responsibility.

In this way, the promotion of the ethical instruction, in the processes of professional formation, oriented to education in and for Peace. From which not only remain attached to a temporary review in a preliminary exercise to the professionalization of a path of academic disciplinary training; but that this, in turn, was present in the subsequent spaces, during, and within the segments of sequential instruction, in the advancement of professional training. Besides being promoted, from a platform, of constant reference to the own ethical dimension, as a preliminary axis, in processes of education for Peace.

\section{References}

[1] Camps, V. (1998). The school faced with the challenge of practical knowledge. Childhood and learning, 21 (82), 65-73.

[2] Markova, S., Depsames, L., Burova, I., Tsyplakova, S., \& Chigarov, E. (2017). Role of education in development of professional values of specialists. Journal of Entrepreneurship Education, 20 (3).

[3] Segreda, A. M., Llavador, J. B., \& Bajos, E. I. (2014). University social responsibility, the challenge of its permanent construction. Iberoamerican Journal of Higher Education, 5 (14).

[4] Marradi, A., Achenti, N. and Piovani, J. (2010). Methodology of Social Sciences, Cengage Learning, Buenos Aires, Argentina.

[5] Ruiz Olabuénaga, J. (2012). Methodology of qualitative research, University of Deusto, Spain.

[6] Navarro, G., Boero, P., Jiménez, G., Tapia, L., Hollander, R., Escobar, A., \& Espina, Á. (2018). University students and social responsibility. Quality in Education, (33), 101-121.

[7] Lotz-Sisitka, H. (2014). UNESCO World Conference on Education for Sustainable Development. In Report of the conference prepared by the General Rapporteur. Retrieved from http: // unesdoc. unesco org / images / 0023/002328 S (Vol. 232888).

[8] Porter, M. E. and Kramer, M. R. (2006), "Strategy and society: The link between competitive advantage and corporate social responsibility", Harvard Business Review, pp. 1-15.

[9] Lanz, R. (2010). Ten questions about transdisciplina. RET. Journal of Transdisciplinary Studies, 2 (1).

[10] Morett, L. O. (2010). Traditional knowledge and innovation: transdisciplinary challenges. In Philosophical Observations on Transdisciplinarity (pp. 107-129).

[11] Haavelslrud, M. (2015). Three Roots of the Transdisciplinary Analysis in Education for Peace. PROSPECTIVE. Journal of Social Work and Social Intervention, (20), 45-70.

*Corresponding author.

E-mail address: ingabwetrust@ hotmail.com 